\title{
NIH to lay down the law
}

\section{Washington}

FEDERAL rules governing the use of animals for biomedical research in the United States are to be strengthened, although a series of inspections by the National Institutes of Health (NIH) has found existing procedures to be working well. NIH have published draft rules which would make compliance with their animal welfare principles mandatory for institutions receiving $\mathrm{NIH}$ funds. The rules, which may be amended after a period of public comment, also provide for closer NIH monitoring of grantee institutions and for a stronger role for the animal research committees (ARCs) within universities and research institutions.

The rules were unveiled last week at an unusual conference at the National Academy of Sciences. Participants discussed the ethics of using animals in research, and humans whose lives had been saved as a result of such research gave impassioned testimony of the importance of continuing to use animals. Dr Edward Brandt, US Assistant Secretary for Health, praised the scientific community for its "responsible conduct" in the use of animals. Contemporary science, he said, is more sensitive than ever to the need for a humane approach, but this heightened sensitivity should be reflected in "stronger, more precise administrative arrangements within grantee institutions themselves".

While present NIH guidelines say research institutions seeking NIH support must express their "commitment to comply" with NIH's principles for the use of animals, the new regulations insist that institutions must regard the principles as mandatory. The regulations also provide for a more active NIH role in ensuring that the principles are indeed implemented. Institutions which choose not to seek accreditation by the American Association for Accreditation of Laboratory Animal Care (AAALAC) will have to submit annual reports describing their policy towards animals in research. They will also be subject to random inspections by Public Health Service staff.

The principles themselves have been altered little, although NIH warn that changes may follow a decision to adopt standard government-wide policies as a result of current interagency discussions. At present, NIH set out a dozen short principles covering the personnel permitted to use animals in research, the purpose and conduct of the research and the facilities in which animals are housed and transported.

Experiments involving live vertebrate animals, for example, must be performed under the supervision of a qualified scientist; and the housing, care and feeding of experimental animals must be supervised by a qualified veterinarian. The research should be "such as to yield fruitful

results for the good of society and not random or unnecessary". Experiments should be conducted to avoid "all unnecessary suffering and injury". When it does not invalidate the experiment, and when it will reduce discomfort, experimental animals are to be anaesthetized under the supervision of a senior scientist.

A significant change in existing policy, and one that may cause organizational problems, is a call for a stronger and betterdefined role for ARCs. Visits to ten universities and research institutions last year apparently convinced NIH that although all institutions had set up such committees, many were "less than fully assertive" in exercising their responsibilities. As a resuit, the new regulations contain more specific membership requirements and set out the ARCs' role in considerable detail.

Existing rules say ARCs must have at least five members and a veterinarian. The new rules say each committee must include an individual not affiliated with the insti-

\section{US science teaching}

\section{Texan textbooks evolve}

\section{Washington}

THE Texas board of education last week repealed its decade-old textbook regulations, which have required school textbooks to present evolution as only one of several explanations of the origins of mankind, and in a manner "not detrimental to other theories of origin". The rules, which have been blamed for widespread changes in biology textbooks throughout the United States, were declared unconstitutional last month by the Texas state attorney general, Mr Jim Mattox.

In a non-binding opinion, Mr Mattox said the rules had been motivated by a concern for religious sensibilities rather than for scientific truth, and therefore violated the constitutional separation of church and state. The board of education voted overwhelmingly last week to repeal the regulations. The decision means that publishers will no longer be required to print a statement on the introductory page of textbooks that any material on evolution "is presented as theory rather than fact". And it is also now easier for opponents of creationism to argue before the Texas board for the rejection of texts that have reduced or dropped references to evolution.

Pressure to repeal the Texas rules came principally from People for the American Way, a liberal pressure group committed to the separation of church and state. Like many southern states, Texas insists that all textbooks used in its schools must first be approved by the state board. Because Texas spends more than $\$ 60$ million a year on textbooks, 10 per cent of the nation's tution, a non-scientist and a practising scientist experienced in laboratory animal medicine. The committees would have extensive responsibilities. They would have oversight of an institution's general treatment of research animals, and the right to stop research projects that fail to comply with their policies. ARCs would also be expected to review all research proposals to approve the approach to animal welfare. They will not, NIH emphasize, be expected to consider scientific merit.

Few organizations have had time to assess the likely impact of the new regulations. But Ms Carol Scheman, director of federal relations for health and biomedical research at the Association of American Universities, expressed concern about the ability of ARCs to recruit members willing to deal with the large volume of work expected of them. She also warned that if the undeclared aim of the new regulations was to compel all institutions to meet the stringent standards of AAALAC, the cost could prove staggering. In 1982, NIH themselves estimated that the cost to their grantees of such an effort could exceed $\$ 500$ million.

Peter David

textbook market, the rules have exerted enormous pressure on publishers.

The group claims that since the rules first went into effect, many textbook publishers have decreased or even eliminated their coverage of evolution. An analysis by Dr Gerald Skoog of Texas Tech University found that space devoted to evolution in school texts has dropped by as much as a half since the mid-1970s.

Peter David

\section{Prison for fraud}

\section{Washington}

THREE US scientists convicted last October of falsifying the results of tests conducted under contract for the federal government are to go to prison. Announcing that he was "sending a message" to the scientific community, US District Judge John Nordberg last week imposed prison sentences on three employees of the nowdefunct Industrial Bio-Test Laboratories Inc. in Chicago.

Dr Moreno Keplinger, former head of toxicology at the laborntory, was sentenced to a year in prison and four years of probation. Mr James Plank, assistant toxicology manager, and Mr Paul Wright, head of the rat toxicology section, received sentences of six months in prison and two years probation.

The three were found guilty of faking the results of experiments designed to assess the safety of an antiarthritis drug, a pesticide and an antibacterial agent used in soap (see Nature 303, 738; 1983). The sentences were stayed pending appeals.

Peter David 